\title{
1 PUFA and Oxidative Stress. Differential Modulation of the Cell Response by DHA
}

\section{Mattia Di Nunzio ${ }^{1, *}$, Veronica Valli ${ }^{2}$, Alessandra Bordoni ${ }^{1,2}$}

1 Interdepartmental Centre for Industrial Agri-Food Research, University of Bologna, piazza Goidanich, 60 Cesena (FC) - 47521, Italy; E-Mail: mattia.dinunzio@ unibo.it (M.D.N.); alessandra.bordoni@unibo.it (A.B.)

2 Department of Agri-Food Science and Technology, University of Bologna, piazza Goidanich, 60 47521 Cesena (FC) - 47521, Italy; E-Mails: veronica.valli9@unibo.it (V.V); alessandra.bordoni@unibo.it (A.B.)

* Author to whom correspondence should be addressed; E-Mail: mattia.dinunzio@ unibo.it; Tel.: +39-0547-338957; Fax: +39-0547-382348.

\begin{abstract}
:
Although an increased dietary intake of long-chain n-3 PUFA is considered an effective preventive strategy, a theoretical concern related to the possible increase of lipid peroxidation induced by a PUFA-rich diet still remains. In this study, the effects of different PUFA (linoleic, $\alpha$-linolenic, arachidonic, eicosapentaenoic, and docosahexaenoic acid) on cytotoxicity, lipid oxidation, and modulation of antioxidant defenses were evaluated in HepG2 cells submitted to an oxidative stress $\left(\mathrm{H}_{2} \mathrm{O}_{2}\right)$. Results clearly evidenced that all supplemented PUFA but DHA enhanced cell susceptibility to $\mathrm{H}_{2} \mathrm{O}_{2}$. Overall, our results underline that PUFA cannot be considered as a single category but as individual compounds, and research on mechanisms of action and preventive effects should deal with the individual fatty acids, particularly in the case of DHA.
\end{abstract}

Keywords: HepG2 cells; hydrogen peroxide; cytotoxicity; antioxidant enzymes

\section{Introduction}

There are converging opinions among experts, organizations and health professionals that a recommendation for a daily individual consumption of $500 \mathrm{mg}$ of eicosapentaenoic (EPA)/ docosahexaenoic (DHA) acids would provide health benefits (Salem \& Eggersdorfer, 2015). An increased dietary intake of n-3 long-chain polyunsaturated fatty acids (n-3 LC-PUFA), EPA and DHA, is considered an effective strategy in the prevention and modulation of cardiovascular (Ohnishi \& Saito, 2013; Cao et al., 2015) and neurological diseases (Patrick \& Ames, 2015), for the optimization of cognitive performance (Muldoon et al., 2014) and brain development (Brenna \& Carlson, 2014). 
Since DHA and other PUFA are highly oxidizable molecules (Miyashita, 2014), a theoretical concern remains on their use at high concentration in the prevention of chronic diseases having the oxidative stress as one of the underlying mechanisms.

Besides being prone to oxidation, PUFA have been reported to activate the stress-signaling pathway controlling the genetic program used by cells to induce the synthesis of proteins responsible for detoxification and counteraction of the oxidative stress (Ma, 2013). In this way, PUFA can modulate the activity of antioxidant enzymes (Wang et al., 2004) to ensure survival and reduced status.

Supplementing cultured cells with individual PUFA we previously observed diverse effects on oxidation and modulation of antioxidant defenses. The different effects were not simply related to the length of the carbon chain, or to the number and position of double bonds in the fatty acid (Di Nunzio et al., 2011). In particular, DHA supplementation did not cause any adverse effect, suggesting that its use as preventive dietary strategy does not induce a higher sensitivity to oxidation. It is conceivable that the overall effects of the different PUFA are related to their individual ability to increase the intracellular concentration of pro- or antioxidants.

In this light, the concomitant oxidative status of the cell could have a role in its response to PUFA supplementation, and the differential effect of DHA than other PUFA needs to be confirmed in cells submitted to an oxidative insult. To evaluate it, in the present work, we supplemented HepG2 cells with linoleic acid (18:2n-6, LA), $\alpha$-linolenic acid (18:3n-3, ALA), arachidonic acid (20:4n-6, ARA), eicosapentaenoic acid (20:5n-3, EPA), and docosahexaenoic acid (22:6n-3, DHA), then a mild oxidative stress reflecting physiological condition was induced (Halliwell et al., 2000; GonzálezFlecha et al., 1993; Khassaf et al., 2001). HepG2 cells were used as model system since liver is a major organ attacked by reactive oxygen species (ROS) (Sànchez-Valle et al., 2012), and parenchymal cells are primary cells subjected to oxidative stress induced injury in the liver. Cells were supplemented with physiological concentration $(60 \mu \mathrm{M})$ of $\mathrm{n}-6$ and $\mathrm{n}-3$ PUFA, and cell survival, lipid oxidation, and antioxidant defenses were evaluated after exposure to hydrogen peroxide.

\section{Experimental Section}

\subsection{Chemical}

Dulbecco's modified Eagle's medium (DMEM), and Dulbecco's phosphate-buffered saline (DPBS) were purchased from Lonza (Milan, Italy). All chemicals and solvents were of the highest analytical grade and were purchased from Sigma-Aldrich (Milan, Italy).

\subsection{HepG2 cells tissue culture}

HepG2 human hepatoma cells were maintained at $37^{\circ} \mathrm{C}, 95 \%$ air, $5 \% \mathrm{CO}_{2}$ in DMEM supplemented with $10 \%(\mathrm{v} / \mathrm{v})$ fetal calf serum, $100 \mathrm{U} / \mathrm{ml}$ penicillin and $100 \mu \mathrm{g} / \mathrm{ml}$ streptomycin (Di Nunzio et al., 2010). Once a week cells were split 1:20 into a new $75 \mathrm{~cm}^{2}$ flask, and medium was refreshed after $72 \mathrm{~h}$.

\subsection{Fatty acid supplementation and oxidative stress}

Cells were seeded in 6-well plates, and after 24 hours, at $75-80 \%$ confluence, they were incubated for $21 \mathrm{~h}$ with the different fatty acids at $60 \mu \mathrm{M}$ concentration. Free fatty acids were dissolved in $100 \%$ 
isopropanol, and complexed to bovine serum albumin (BSA). Fatty acid-BSA complexes were prepared fresh each time, and BSA final concentration was $0.5 \%$ in serum free DMEM. Unsupplemented (US) cells received corresponding amounts of BSA and isopropanol, which final concentration in the media was kept below $1 \%(\mathrm{v} / \mathrm{v})$. LA, ALA, ARA, EPA, and DHA were used for cell supplementation. After $21 \mathrm{~h}$ incubation cells were washed twice with warm DPBS, and then exposed for 20 or 60 min to $0.2 \mathrm{mM} \mathrm{H}_{2} \mathrm{O}_{2}$ in Earle's Balanced Salt Solution (EBSS) (116 mM NaCl, $5.4 \mathrm{mM} \mathrm{KCl}, 0.8 \mathrm{mM} \mathrm{NaH} \mathrm{PO}_{4}, 26 \mathrm{mM} \mathrm{NaHCO}, 2.38 \mathrm{mM} \mathrm{CaCl}, 0.39 \mathrm{mM} \mathrm{MgSO}$ ). Some unsupplemented cells received EBSS only (control cells). Then EBSS medium was collected, centrifuged at $400 \mathrm{~g}$ for $3 \mathrm{~min}$, and used to evaluate LDH release and TBARS concentration. Cells were washed twice with warm DPBS, and processed for further analysis.

\subsection{Lactate dehydrogenase $(L D H)$ release}

LDH activity in the EBSS was assessed following spectrophotometrically for 1 min the rate of $\mathrm{NADH}$ oxidation at $340 \mathrm{~nm}$ (Di Nunzio et al., 2013), and enzyme activity was expressed as mUnits/ml.

\subsection{Thiobarbituric acid reactive substances (TBARS) concentration}

TBARS, the end products of lipid peroxidation, were assayed in EBSS as previously reported by Valli et al. (Valli et al., 2012), and their concentration was expressed as relative fluorescence units (RFU) normalized for mg protein in the corresponding well.

\subsection{Cell viability}

Cell viability was evaluated by the 3-(4,5-dimethyldiazol-2-yl)-2,5-diphenyltetrazolium bromide (MTT) assay, based on the cleavage of the yellow tetrazolium salt MTT to purple formazan crystal by metabolic active cells (Danesi et al., 2011). Results were expressed as percent of control cell viability, assigned as $100 \%$.

\subsection{Conjugated diene $(C D)$ level}

Cellular level of CD containing lipids was assayed as reported by Di Nunzio et al. (Di Nunzio et al., 2011), and expressed as percent of the value detected in control cells, assigned to $100 \%$.

\subsection{Cytoplasmic total antioxidant activity (TAA)}

Cytoplasmic TAA was measured as reported by Di Nunzio et al. (Di Nunzio et al., 2013), based on the ability of the antioxidant molecules in the sample to reduce the radical cation of ABTS. Values were normalized for protein content in the sample, and expressed as micromoles of trolox equivalent (TE)/mg protein. 
103 Cytoplasmic GSH content was determined as previously described (Valli et al., 2012), normalized 104 for protein content in the sample, and expressed as nmoles of GSH/mg protein.

105

106

107

108

109

110

111

112

113

114

115

116

117

118

119

120

121

122

123

124

125

126

127

128

129

130

131

132

133

134

135

136

\subsection{Antioxidant enzymes activity}

Cytoplasmic superoxide dismutase (SOD) activity was assayed using a commercial kit (Cayman Chemical, Michigan, USA) following the manufacture instructions. SOD activity (Units) was then normalized for $\mathrm{mg}$ of protein in the sample. Cytoplasmic catalase (CAT) activity was assayed spectrophotometrically at $240 \mathrm{~nm}$ following the extinction of $\mathrm{H}_{2} \mathrm{O}_{2}$ (Danesi et al., 2006), normalized for protein content in the sample, and expressed as Units/mg protein. Cytoplasmic glutathione-Stransferase (GST) activity was assayed as previously reported by Di Nunzio et al. (Di Nunzio et al., 2011). GST activity (nmol/min) was then normalized for protein content in the sample. Cytoplasmic glutathione peroxidase (GPx) activity was assayed using a commercial kit (Cayman Chemical, Michigan, USA) following the manufacture instructions. GPx activity ( $\mathrm{nmol} / \mathrm{min}$ ) was then normalized for protein content in the sample.

\subsection{Protein content}

Protein content was determined according to Bradford (Bradford, 1976), using BSA as standard.

\subsection{Statistical analysis}

Data are reported as mean \pm SD of at least six samples derived from three independent cell cultures. Statistical analysis was by the one way ANOVA with Dunnett as post-test.

\section{Results}

To evidence the detrimental effect of $\mathrm{H}_{2} \mathrm{O}_{2}$ addition, control cells were compared to stressed cells, both US and fatty acid supplemented. Then a statistical comparison was performed among stressed cells, to verify the differential effect of the single fatty acids, and to evidence whether the diverse supplementation could protect or exacerbate the outcomes of the oxidative stress.

\section{1. $\mathrm{H}_{2} \mathrm{O}_{2}$-induced cell oxidative damage}

The $\mathrm{H}_{2} \mathrm{O}_{2}$-induced cell damage was evaluated by measuring cell viability, LDH release, TBARS level and $\mathrm{CD}$ content (figure 1). As shown in figure 1A, in all cells $\mathrm{H}_{2} \mathrm{O}_{2}$ exposure caused a significant reduction of viability with respect to controls. Among stressed cells, viability decreased in all supplemented cells, but DHA.

The oxidative stress caused a significant increase in LDH activity and TBARS concentration in the medium of all cells except the US and DHA supplemented ones (figure 1B and 1C, respectively). Notwithstanding the increase of TBARS in almost all stressed cells, the level of CD, the first products of lipid peroxidation, increased in LA and ARA supplemented cells only (figure 1D).

\subsection{Modulation of antioxidant defenses}


To evaluate the effect of PUFA supplementation on the cell response to an oxidative stress, cytosolic TAA and GSH content (figure 2), and the activity of SOD, CAT, GST and GPx enzymes (figure 3) were determined.

Compared to controls, $\mathrm{H}_{2} \mathrm{O}_{2}$ exposure caused a significant decrease of cytosolic TAA in US and LA supplemented cells only (figure 2A), and no modification in GSH content apart from a significant increase in DHA supplemented cells (figure 2B). Comparing stressed cells, TAA appeared higher in ARA and DHA supplemented hepatocytes, the latter also showing a higher GSH concentration.

Compared to controls, upon $\mathrm{H}_{2} \mathrm{O}_{2}$ exposure a significant increase of SOD activity was detected in LA and n-3 PUFA supplemented cells (figure 3A), and CAT activity increased in all cells (figure 3B). GST activity was not modified in US cells, while it significantly increased in all supplemented cells but DHA ones (figure 3C). Furthermore, a significant increase in GPx activity was detected in LA supplemented cells only (figure 3D). Comparing stressed cells, a differential influence of the supplemented fatty acids on enzyme activities was evidenced. SOD activity being higher in EPA and DHA supplemented, CAT in ARA and EPA supplemented, GST in ARA supplemented, and GPx in LA supplemented cells than in US ones.

Since cellular oxidative status may be influenced by nonlethal oxidative stress exposure in a time depending manner (Brunk et al., 1995), SOD, CAT, GST and GPx activities were also evaluated after 20 min $\mathrm{H}_{2} \mathrm{O}_{2}$ exposure (figure $4 \mathrm{~A}, 4 \mathrm{~B}, 4 \mathrm{C}$ and $4 \mathrm{D}$ respectively).

Compared to controls, upon the shorter $\mathrm{H}_{2} \mathrm{O}_{2}$ exposure time SOD activity increased in ARA and EPA supplemented cells only, and no significant modification in CAT and GPx activity was detected. GST activity was reduced in all supplemented cells except DHA and US ones. Comparing stressed cells a differential effect of the supplementation on SOD, CAT and GST activities was still detected, while no differences were evidenced in GPx activity.

\section{Discussion}

n-6 and n-3 PUFA are well known for their physiological functions and preventive actions (Liu et al., 2015; Pelliccia et al., 2013) that are ascribable to different mechanisms including regulation of membrane functionality, cell signaling, and gene expression (Robichaud \& Surette, 2015; Righi et al., 2011; Bordoni et al., 2007). In contrast to their health effects, PUFAs are known to be prone to rapid peroxidation, which has been shown to impair membrane functions and inactivate proteins and enzymes, eventually leading to various disorders and diseases (Csala et al., 2015). To explain this apparent oxymoron, it has been speculated that the lipid peroxidation occurring in PUFA-rich cells causes a low level, sub-toxic stress that could induce a protective adaptations over time (i.e. hormesis), contributing to PUFA health effects. Actually, n-3 PUFA have been shown to up-regulate the antioxidant systems in various cells (Giordano \& Visioli, 2014), so counteracting the oxidative stress (Zanatta et al., 2014; Tourtas et al., 2012). Although different PUFA share common chemical characteristics, in a previous work we evidenced that they differently modulate the activity of antioxidant enzymes, and have a different impact on cell oxidative status (Di Nunzio et al., 2011). A concomitant oxidative stress could have an impact on the effects of PUFA, this representing an important issue since a higher intake of PUFA, particularly n-3 PUFA, is suggested for the 
(Fischer \& Maier, 2015; Reuter et al., 2010; Pashkow, 2011; Salomone et al., 2016). To further elucidate it, in the present work we have supplemented different PUFA to HepG2 cells, which were then submitted to a mild oxidative stress.

Results herein reported clearly evidence that the cell response to a subsequent oxidative stress can be modulated by a preceding PUFA supplementation.

All supplemented fatty acids except DHA enhance cell susceptibility to $\mathrm{H}_{2} \mathrm{O}_{2}$. This could be due to an increased lipid peroxidation inducing disturbance of fine structures, alteration of integrity, fluidity, and permeability, and functional loss of biomembranes, and generates potentially toxic products (Ayala et al., 2014), as indicated by the increase in TBARS concentration in the medium of all supplemented cells but DHA supplemented ones. Since CD containing lipids, the first products of lipid peroxidation, are usually quickly cleaved to their corresponding breakdown products (Yin et al., 2011), the higher CD concentration in n-6 PUFA than n-3 PUFA supplemented hepatocytes could indicate a longer time lasting lipoperoxidation.

Although we already observed a PUFA sensitizing effect in basal condition (Di Nunzio et al., 2011), results herein reported cannot be simply considered as its consequence but as an additive effect due to the concomitant presence of PUFA and $\mathrm{H}_{2} \mathrm{O}_{2}$. It can be clearly evidenced comparing present and previous data; as example, in basal condition LDH release was significantly higher in ARA supplemented cells only (Di Nunzio et al., 2011), while it is significantly increased in all supplemented cells except DHA ones after $\mathrm{H}_{2} \mathrm{O}_{2}$ addition, the increase being higher in ARA supplemented cells. It is worth noting that DHA supplementation has no adverse effect either in basal condition (Di Nunzio et al., 2011) or after the oxidative insult.

This differential modulation of the cell response to the oxidative stress is in part ascribable to the modulation of the antioxidant enzymes activities. The effect of PUFA on the antioxidant enzymes status have been extensively studied leading to controversial results. To the Authors knowledge, previous studies have been performed using fish oil (Avramovic et al., 2012; Romieu et al., 2008) or other oils (Umesha \& Naidu, 2015; Taranu at al., 2014; Haggag et al., 2014) containing different combinations of PUFA, this not allowing to extrapolate the effect of the single fatty acid. Results herein reported clearly evidence that each fatty acid has specific modulatory effects on antioxidant enzymes, and promotes a specific profile of antioxidant enzyme activities that cannot be predicted using oils containing different proportion of PUFA. The importance of the proportion of PUFA in a mixture has been also shown by Molinar-Toribio et al. (Molinar-Toribio et al., 2015) who evidenced in rat supplemented with EPA plus DHA mixtures that the activity of antioxidant enzymes increases with magnitudes depending on the EPA:DHA ratio. Notably, the highest DHA concentration reduced the oxidative stress.

Our study confirms that exposure time to $\mathrm{H}_{2} \mathrm{O}_{2}$ modulates anti-oxidant enzymes activity, as previously reported by Shull et al. (Shull et al., 1991) and Franco et al. (Franco et al., 1999). In addition, our results evidence that PUFA supplementation exacerbates this time-depending modulation. Assuming that the observed increased activity of antioxidant enzymes is based on an increased transcription of the corresponding encoding genes and an increased synthesis of the enzymatic proteins, a lag time between the insult and the cell response is conceivable. This can explain the less evident changes in antioxidant enzymes activities after 20 than 60 min $\mathrm{H}_{2} \mathrm{O}_{2}$ exposure. In addition, the weaker cell response after shorter time of exposure could be due to the lower intracellular 
concentration of $\mathrm{H}_{2} \mathrm{O}_{2}$. In fact, $\mathrm{H}_{2} \mathrm{O}_{2}$ diffusion across the plasma membrane is low during the first 10 minutes of exposure (Alexandre et al., 2006).

Oxidative stress underlies a complex array of metabolic alterations. Under this condition, derangement of cell biochemistry and function is known to involve misregulation of key components responsible for cell signaling, such as membrane receptors, kinases, phosphatases, and transcription factors (Leonarduzzi et al., 2011; Brigelius-Flohé et al., 2011). In this view, the overall differential effect of supplemented DHA could rely on different mechanisms. Among them, a different extent of incorporation/metabolism of the supplemented fatty acid inside the cell. Although all supplemented PUFA are readily incorporated by HepG2 cells at the expense of monounsaturated fatty acids, in a previous work we observed different conversion rate (Di Nunzio et al., 2010). LA and ALA are further metabolized upon cellular uptake, and EPA is partially desaturated/elongated to DHA. On the contrary, no DHA retro-conversion is detected. Therefore the effects of all PUFA except DHA could be ascribable to both the supplemented PUFA and its derivatives. The differential metabolism of supplemented PUFA could also impact on the modification of membrane composition, and consequently functionality, since the majority of PUFA is incorporated in the cell membrane phospholipids (Abbott et al., 2012). The oxidative stress may selectively impair cell PUFA concentration, which in turn may modulate the effect of the oxidative stress (Zaloga et al., 2006). Oxidative condition modifies fatty acid composition in neonatal rat cardiomyocytes (Bordoni et al., 2005), and a slight increase in the saturated and a decrease in monounsaturated and PUFA content has been detected in the liver of pro-oxidant pesticide-treated rats (Nakbi et al., 2010). At membrane level, exposure to an oxidative stress leads not only to fatty acid oxidation but also to phospholipid breakdown due to activation of phospholipase $A_{2}$ (Nalbone et al., 1990). DHA released from phospholipids is the substrate for the formation of resolvins and protectins, that act through distinct receptors to unfold biological effects (Calder, 2015) including oxidation preventing effects (Liu et al., 2014; Tian et al., 2015).

A higher DHA cellular content may play an important role in the protection from oxidative damage because 4-hydroxyhexenal, an aldehyde derived from DHA peroxidation, up-regulates Nrf2-HO-1 antioxidant signaling pathway, which induces antioxidant effects (Gao et al., 2007).

Many studies indicate that PUFA, particularly EPA and DHA, control gene expression also by directly governing the transcription/activity of peroxisome proliferator-activated receptor-alpha (PPAR $\alpha$ ) (Di Nunzio et al., 2009; Georgiadi et al., 2012), whose activation may result in enhanced expression/activity of antioxidant enzymes such as CAT and SOD (Toyama et al., 2004; Inoue et al., 2001). PPARs exert their effect on gene transcription by dimerization with the 9-cis retinoic acid receptors (RXRs) (Feige et al., 2005). RXR is also able to bind PUFA, mainly DHA (Crawford et al., 2003). Other PUFAs such as EPA or ARA can activate RXR but with lower efficiency (Egea et al., 2002). Thus, DHA can be considered a more efficient activator of PPAR $\alpha$ (Bordoni et al., 2006).

In conclusion, based on reported results each PUFA seems to possess specific pro- and antioxidative characteristics, not predictable on chemical basis such as the length of the carbon chain or the unsaturation degree. According to many in vivo (Mas et al., 2010; Patten et al., 2013) and in vitro (González-Périz et al., 2006; Mukherjee et al., 2004) studies, DHA appears the only fatty acid not increasing cell susceptibility to $\mathrm{H}_{2} \mathrm{O}_{2}$, although its effect is not ascribable to a stronger induction of antioxidant enzymes activity. 
Overall, results herein reported clearly evidence that fatty acid supplementation can modify the cell response to an oxidative stress, and the response is dependent on the supplemented fatty acid. We are beginning to understand the physiology and molecular basis of the effects of n-3 and n- 6 fatty acids, and thereby gradually encompass the full biological potential of these compounds. Our results underline that PUFA cannot be considered as a single category, but as individual compounds. It appears particularly evident for DHA, and although observed results must be confirmed in vivo, this apparent "DHA paradox" represents an important step ahead in the use of DHA supplementation as preventive strategy in the clinical practice.

\section{Disclosure statement}

The authors declare no conflict of interest.

\section{Funding statement}

This work was partially supported by a grant of Italian MIUR (RFO A.B.), of Italian Ministry of 273 Economic Development (Industria 2015 - MIAOVER50 project). The research leading to these results 274 has received funding from the European Union Seventh Framework Programme (FP7/2007-2013) 275 under grant agreement $\mathrm{n}^{\circ}$ 311876: Pathway-27.

\section{References}

1. Abbott SK, Else PL, Atkins TA, Hulbert AJ. 2012. Fatty acid composition of membrane bilayers: importance of diet polyunsaturated fat balance. Biochim Biophys Acta. 1818:13091317.

2. Alexandre J, Batteux F, Nicco C, Chéreau C, Laurent A, Guillevin L, Weill B, Goldwasser F. 2006. Accumulation of hydrogen peroxide is an early and crucial step for paclitaxel-induced cancer cell death both in vitro and in vivo. Int J Cancer. 119:41-48.

3. Avramovic N, Dragutinovic V, Krstic D, Colovic M, Trbovic A, de Luka S, Milovanovic I, Popovic T. 2012. The effects of omega 3 fatty acid supplementation on brain tissue oxidative status in aged wistar rats. Hippokratia. 16:241-245.

4. Ayala A, Muñoz MF, Argüelles S. 2014. Lipid peroxidation: production, metabolism, and signaling mechanisms of malondialdehyde and 4-hydroxy-2-nonenal. Oxid Med Cell Longev. 2014:360438.

5. Bordoni A, Angeloni C, Leoncini E, Danesi F, Maranesi M, Biagi PL, Hrelia S. 2005. Hypoxia/reoxygenation alters essential fatty acids metabolism in cultured rat cardiomyocytes: protection by antioxidants. Nutr Metab Cardiovasc Dis. 15:166-73.

6. Bordoni A, Astolfi A, Morandi L, Pession A, Danesi F, Di Nunzio M, Franzoni M, Biagi P, Pession A. 2007. N-3 PUFAs modulate global gene expression profile in cultured rat cardiomyocytes. Implications in cardiac hypertrophy and heart failure. FEBS Lett. 581:923-929.

7. Bordoni A, Di Nunzio M, Danesi F, Biagi PL. 2006. Polyunsaturated fatty acids: From diet to binding to ppars and other nuclear receptors. Genes Nutr. 1:95-106. 
8. Bradford MM. 1976. A rapid and sensitive method for the quantitation of microgram quantities of protein utilizing the principle of protein-dye binding. Anal Biochem. 72:248-254.

9. Brenna JT, Carlson SE. 2014. Docosahexaenoic acid and human brain development: evidence that a dietary supply is needed for optimal development. J Hum Evol. 77:99-106.

10. Brigelius-Flohé R, Flohé L. 2011. Basic principles and emerging concepts in the redox control of transcription factors. Antioxid Redox Signal. 15:2335-2381.

11. Brunk UT, Zhang H, Dalen H, Ollinger K. 1995. Exposure of cells to nonlethal concentrations of hydrogen peroxide induces degeneration-repair mechanisms involving lysosomal destabilization. Free Radic Biol Med. 19:813-822.

12. Calder PC. 2015. Marine omega-3 fatty acids and inflammatory processes: Effects, mechanisms and clinical relevance. Biochim Biophys Acta. 1851:469-484.

13. Cao Y, Lu L, Liang J, Liu M, Li X, Sun R, Zheng Y, Zhang P. 2015. Omega-3 Fatty Acids and Primary and Secondary Prevention of Cardiovascular Disease. Cell Biochem Biophys. 72:77-81.

14. Crawford MA, Golfetto I, Ghebremeskel K, Min Y, Moodley T, Poston L, Phylactos A, Cunnane S, Schmidt W. 2003. The potential role for arachidonic and docosahexaenoic acids in protection against some central nervous system injuries in preterm infants. Lipids. 38:303-315.

15. Csala M, Kardon T, Legeza B, Lizák B, Mandl J, Margittai É, Puskás F, Száraz P, Szelényi P, Bánhegyi G. 2015. On the role of 4-hydroxynonenal in health and disease. Biochim Biophys Acta. 1852:826-838.

16. Danesi F, Ferioli F, Caboni MF, Boschetti E, Di Nunzio M, Verardo V, Valli V, Astolfi A, Pession A, Bordoni A. 2011. Phytosterol supplementation reduces metabolic activity and slows cell growth in cultured rat cardiomyocytes. Br J Nutr. 106:540-548.

17. Danesi F, Malaguti M, Di Nunzio M, Maranesi M, Biagi PL, Bordoni A. 2006. Counteraction of adriamycin-induced oxidative damage in rat heart by selenium dietary supplementation. $\mathrm{J}$ Agric Food Chem. 54:1203-1208.

18. Di Nunzio M, Danesi F, Bordoni A. 2009. n-3 PUFA as regulators of cardiac gene transcription: a new link between PPAR activation and fatty acid composition. Lipids. 44:1073-1079.

19. Di Nunzio M, Toselli M, Verardo V, Caboni MF, Bordoni A. 2013. Counteraction of oxidative damage by pomegranate juice: influence of the cultivar. J Sci Food Agric. 93:3565-3573.

20. Di Nunzio M, Valli V, Bordoni A. 2011. Pro- and anti-oxidant effects of polyunsaturated fatty acid supplementation in HepG2 cells. Prostaglandins Leukot Essent Fatty Acids. 85:121-127.

21. Di Nunzio M, van Deursen D, Verhoeven AJ, Bordoni A. 2010. n-3 and n-6 Polyunsaturated fatty acids suppress sterol regulatory element binding protein activity and increase flow of nonesterified cholesterol in HepG2 cells. Br J Nutr. 103:161-167.

22. Egea PF, Mitschler A, Moras D. 2002. Molecular recognition of agonist ligands by RXRs. Mol Endocrinol. 16:987-997.

23. Feige JN, Gelman L, Tudor C, Engelborghs Y, Wahli W, Desvergne B. 2005. Fluorescence imaging reveals the nuclear behavior of peroxisome proliferator-activated receptor/retinoid $\mathrm{X}$ receptor heterodimers in the absence and presence of ligand. J Biol Chem. 280:17880-17890.

24. Fischer R, Maier O. 2015. Interrelation of oxidative stress and inflammation in neurodegenerative disease: role of TNF. Oxid Med Cell Longev. 2015:610813. 
25. Franco AA, Odom RS, Rando TA. 1999. Regulation of antioxidant enzyme gene expression in response to oxidative stress and during differentiation of mouse skeletal muscle. Free Radic Biol Med. 27:1122-1132.

26. Gao L, Wang J, Sekhar KR, Yin H, Yared NF, Schneider SN, Sasi S, Dalton TP, Anderson ME, Chan JY, Morrow JD, Freeman ML. 2007. Novel n-3 fatty acid oxidation products activate Nrf2 by destabilizing the association between Keap1 and Cullin3. J Biol Chem. 282:2529-2537.

27. Georgiadi A, Boekschoten MV, Müller M, Kersten S. 2012. Detailed transcriptomics analysis of the effect of dietary fatty acids on gene expression in the heart. Physiol Genomics. 446:352-361.

28. Giordano E, Visioli F. 2014. Long-chain omega 3 fatty acids: molecular bases of potential antioxidant actions. Prostaglandins Leukot Essent Fatty Acids. 90:1-4.

29. González-Flecha B, Cutrin JC, Boveris A. 1993. Time course and mechanism of oxidative stress and tissue damage in rat liver subjected to in vivo ischemia-reperfusion. J Clin Invest. 912:456464.

30. González-Périz A, Planagumà A, Gronert K, Miquel R, López-Parra M, Titos E, Horrillo R, Ferré N, Deulofeu R, Arroyo V, Rodés J, Clària J. 2006. Docosahexaenoic acid DHA blunts liver injury by conversion to protective lipid mediators: protectin D1 and 17S-hydroxy-DHA. FASEB J. 20:2537-2539.

31. Haggag Mel-S, Elsanhoty RM, Ramadan MF. 2014. Impact of dietary oils and fats on lipid peroxidation in liver and blood of albino rats. Asian Pac J Trop Biomed. 4:52-58.

32. Halliwell B, Clement MV, Long LH. 2000. Hydrogen peroxide in the human body. FEBS Letters. 486:10-13.

33. Inoue I, Goto S, Matsunaga T, Nakajima T, Awata T, Hokari S, Komoda T, Katayama S. 2001. The ligands/activators for peroxisome proliferator-activated receptor alpha (PPARalpha) and PPARgamma increase $\mathrm{Cu} 2+, \mathrm{Zn} 2+$-superoxide dismutase and decrease p22phox message expressions in primary endothelial cells. Metabolism. 50:3-11.

34. Khassaf M, Child RB, McArdle A, Brodie DA, Esanu C, Jackson MJ. 2001. Time course of responses of human skeletal muscle to oxidative stress induced by nondamaging exercise. $\mathrm{J}$ Appl Physiol. 90:1031-1035.

35. Leonarduzzi G, Sottero B, Testa G, Biasi F, Poli G. 2011. New insights into redox-modulated cell signaling. Curr Pharm Des. 17:3994-4006.

36. Liu JJ, Green P, John Mann J, Rapoport SI, Sublette ME. 2015. Pathways of polyunsaturated fatty acid utilization: implications for brain function in neuropsychiatric health and disease. Brain Res. 1597:220-246.

37. Liu M, Boussetta T, Makni-Maalej K, Fay M, Driss F, El-Benna J, Lagarde M, Guichardant M. 2014. Protectin DX, a double lipoxygenase product of DHA, inhibits both ROS production in human neutrophils and cyclooxygenase activities. Lipids. 49:49-57.

38. Ma Q. 2013. Role of nrf2 in oxidative stress and toxicity. Annu Rev Pharmacol Toxicol. 53: 401426.

39. Mas E, Woodman RJ, Burke V, Puddey IB, Beilin LJ, Durand T, Mori TA. 2010. The omega-3 fatty acids EPA and DHA decrease plasma F2-isoprostanes: Results from two placebo-controlled interventions. Free Radic Res. 44, 983-990. 
40. Miyashita K. Paradox of omega-3 PUFA oxidation. 2014. Eur J Lipid Sci Technol. 116:12681279.

41. Molinar-Toribio E, Pérez-Jiménez J, Ramos-Romero S, Romeu M, Giralt M, Taltavull N, Muñoz-Cortes M, Jáuregui O, Méndez L, Medina I, Torres JL. 2015. Effect of n-3 PUFA supplementation at different EPA:DHA ratios on the spontaneously hypertensive obese rat model of the metabolic syndrome. Br J Nutr. 113:878-887.

42. Mukherjee PK, Marcheselli VL, Serhan CN, Bazan NG. 2004. Neuroprotectin D1: a docosahexaenoic acid-derived docosatriene protects human retinal pigment epithelial cells from oxidative stress. Proc Natl Acad Sci USA. 101:8491-8496.

43. Muldoon MF, Ryan CM, Yao JK, Conklin SM, Manuck SB. 2014. Long-chain omega-3 fatty acids and optimization of cognitive performance. Mil Med. 179:95-105.

44. Nakbi A, Tayeb W, Grissa A, Issaoui M, Dabbou S, Chargui I, Ellouz M, Miled A, Hammami M. 2010. Effects of olive oil and its fractions on oxidative stress and the liver's fatty acid composition in 2,4-Dichlorophenoxyacetic acid-treated rats. Nutr Metab (Lond). 7:80.

45. Nalbone G, Grynberg A, Chevalier A, Leonardi J, Termine E, Lafont H. 1990. Phospholipase A activity of cultured rat ventricular myocyte is affected by the nature of cellular polyunsaturated fatty acids. Lipids. 25:301-306.

46. Ohnishi H, Saito Y. 2013. Eicosapentaenoic acid EPA reduces cardiovascular events: relationship with the EPA/arachidonic acid ratio. J Atheroscler Thromb. 20:861-877.

47. Pashkow FJ. 2011. Oxidative Stress and Inflammation in Heart Disease: Do Antioxidants Have a Role in Treatment and/or Prevention? Int J Inflam. 2011:514623.

48. Patrick RP, Ames BN. 2015. Vitamin D and the omega-3 fatty acids control serotonin synthesis and action, part 2: relevance for ADHD, bipolar disorder, schizophrenia, and impulsive behavior. FASEB J. 29:2207-2222.

49. Patten AR, Brocardo PS, Christie BR. 2013. Omega-3 supplementation can restore glutathione levels and prevent oxidative damage caused by prenatal ethanol exposure. J Nutr Biochem. 24:760-769.

50. Pelliccia F, Marazzi G, Greco C, Franzoni F, Speziale G, Gaudio C. 2013. Current evidence and future perspectives on n-3 PUFAs. Int J Cardiol. 170:S3-7.

51. Reuter S, Gupta SC, Chaturvedi MM, Aggarwal BB. 2010. Oxidative stress, inflammation, and cancer: how are they linked? Free Radic Biol Med. 49:1603-1616.

52. Righi V, Di Nunzio M, Danesi F, Schenetti L, Mucci A, Boschetti E, Biagi P, Bonora S, Tugnoli V, Bordoni A. 2011. EPA or DHA supplementation increases triacylglycerol, but not phospholipid, levels in isolated rat cardiomyocytes. Lipids. 46:627-636.

53. Robichaud PP, Surette ME. 2015. Polyunsaturated fatty acid-phospholipid remodeling and inflammation. Curr Opin Endocrinol Diabetes Obes. 22:112-118.

54. Romieu I, Garcia-Esteban R, Sunyer J, Rios C, Alcaraz-Zubeldia M, Velasco SR, Holguin F. 2008. The effect of supplementation with omega-3 polyunsaturated fatty acids on markers of oxidative stress in elderly exposed to PM2.5. Environ Health Perspect. 116:1237-1242.

55. Salem N Jr, Eggersdorfer M. 2015. Is the world supply of omega-3 fatty acids adequate for optimal human nutrition? Curr Opin Clin Nutr Metab Care. 18:147-154. 
56. Salomone F, Godos J, Zelber-Sagi S. 2016. Natural antioxidants for non-alcoholic fatty liver disease: molecular targets and clinical perspectives. Liver Int. 36:5-20.

57. Sánchez-Valle V, Chávez-Tapia NC, Uribe M, Méndez-Sánchez N. 2012. Role of oxidative stress and molecular changes in liver fibrosis: a review. Curr Med Chem. 19:4850-4860.

58. Shull S, Heintz NH, Periasamy M, Manohar M, Janssen YM, Marsh JP, Mossman BT. 1991. Differential regulation of antioxidant enzymes in response to oxidants. J Biol Chem. 266:2439824403.

59. Taranu I, Gras M, Pistol GC, Motiu M, Marin DE, Lefter N, Ropota M, Habeanu M. 2014. $\omega-3$ PUFA rich camelina oil by-products improve the systemic metabolism and spleen cell functions in fattening pigs. PLoS One. 9:e110186.

60. Tian Y, Zhang Y, Zhang R, Qiao S, Fan J. 2015. Resolvin D2 recovers neural injury by suppressing inflammatory mediators expression in lipopolysaccharide-induced Parkinson's disease rat model. Biochem Biophys Res Commun. 460:799-805.

61. Tourtas T, Birke MT, Kruse FE, Welge-Lüssen UC, Birke K. 2012. Preventive effects of omega3 and omega- 6 Fatty acids on peroxide mediated oxidative stress responses in primary human trabecular meshwork cells. PLoS One. 7:e31340.

62. Toyama T, Nakamura H, Harano Y, Yamauchi N, Morita A, Kirishima T, Minami M, Itoh Y, Okanoue T. 2004. PPARalpha ligands activate antioxidant enzymes and suppress hepatic fibrosis in rats. Biochem Biophys Res Commun. 324:697-704.

63. Umesha SS, Naidu KA. 2015. Antioxidants and antioxidant enzymes status of rats fed on n-3 PUFA rich Garden cress Lepidium Sativum L seed oil and its blended oils. J Food Sci Technol. 52:1993-2002.

64. Valli V, Gómez-Caravaca AM, Di Nunzio M, Danesi F, Caboni MF, Bordoni A. 2012. Sugar cane and sugar beet molasses, antioxidant-rich alternatives to refined sugar. J Agric Food Chem. 60:12508-12515.

65. Wang HH, Hung TM, Wei J, Chiang AN. 2004. Fish oil increases antioxidant enzyme activities in macrophages and reduces atherosclerotic lesions in apoE-knockout mice. Cardiovasc Res. 61:169-176.

66. Yin H, Xu L, Porter NA. 2011. Free radical lipid peroxidation: mechanisms and analysis. Chem Rev. 111:5944-5972.

67. Zaloga GP, Ruzmetov N, Harvey KA, Terry C, Patel N, Stillwell W, Siddiqui R. 2006. (N-3) long-chain polyunsaturated fatty acids prolong survival following myocardial infarction in rats. $\mathrm{J}$ Nutr. 136:1874-1878.

68. Zanatta AL, Miranda DT, Dias BC, Campos RM, Massaro MC, Michelotto PV Jr, West AL, Miles EA, Calder PC, Nishiyama A. 2014. Fish oil supplementation decreases oxidative stress but does not affect platelet-activating factor bioactivity in lungs of asthmatic rats. Lipids. 49:665675. 

condition and after $1 \mathrm{~h} \mathrm{H}_{2} \mathrm{O}_{2}$ exposure.

Data are means $\pm S D$ of at least six samples in each group, coming from three independent cell cultures. Statistical analysis was by the one-way ANOVA $p<0.001)$ using Dunnett's post-test to compare: 1) stressed cells both US and supplemented) to controls $* p<0.05 ; * * p<0.01 ; * * * p<0.001)$; and 2) supplemented stressed cells to US stressed cells $\left.{ }^{\circ} p<0.05 ;{ }^{\circ 00} p<0.001\right)$.

Figure 2. TAA A) and GSH level B) in basal condition and after $1 \mathrm{~h} \mathrm{H}_{2} \mathrm{O}_{2}$ exposure.

Data are means $\pm S D$ of at least six samples in each group, coming from three independent cell cultures. Statistical analysis was performed by the one-way ANOVA $p<0.01)$ using Dunnett's as posttest to compare: 1) stressed cells both US and supplemented) to controls *p<0.05); and 2) supplemented stressed cells to US stressed cells $\left.{ }^{\circ} p<0.05 ;{ }^{\circ 0} p<0.01\right)$.

Figure 3. SOD A), CAT B), GST C) and GPx D) activity in basal condition and after $1 \mathrm{~h} \mathrm{H}_{2} \mathrm{O}_{2}$ exposure.

Data are means $\pm S D$ of at least six samples in each group, coming from three independent cell cultures. Statistical analysis was performed by the one-way ANOVA A, B and $C p<0.001 ; D p<0.01$ ) using Dunnett's as post-test to compare: 1) stressed cells both US and supplemented) to controls $\left.{ }^{*} p<0.05 ; * * p<0.01 ; * * * p<0.001\right)$; and 2) supplemented stressed cells to US stressed cells ${ }^{\circ} p<0.05$; $\left.{ }^{\circ 0} p<0.01 ;{ }^{\circ 00} p<0.001\right)$.

Figure 4 SOD A), CAT B), GST C) and GPx D) activity in basal condition and after 20 min $\mathrm{H}_{2} \mathrm{O}_{2}$ exposure.

Data are means $\pm S D$ of at least six samples in each group, coming from three independent cell 481 cultures. Statistical analysis was performed by the one-way ANOVA A and B $p<0.01 ; C p<0.001)$ 482 using Dunnett's as post-test to compare: 1) stressed cells both US and supplemented) to controls 
$483 * p<0.05 ; * * p<0.01 ; * * * p<0.001)$; and 2) supplemented stressed cells to US stressed cells ${ }^{\circ} p<0.05$; $\left.484 \quad{ }^{\circ \circ} p<0.01 ;{ }^{\circ 00} p<0.001\right)$. 